\title{
Tratamento interdisciplinar para reabilitação estética complexa do sorriso: relato de
}

\section{caso}

\author{
Interdisciplinary treatment for complex aesthetic rehabilitation of the smile: a case report \\ Tratamiento interdisciplinario para la rehabilitación estética compleja de la sonrisa: reporte de un
}

\author{
André Luiz Marinho Falcão Gondim \\ ORCID: https://orcid.org/0000-0002-3581-419X \\ Universidade Federal do Rio Grande do Norte, Brasil \\ E-mail: algondim@yahoo.com.br \\ Eduardo Miyashita \\ ORCID: https://orcid.org/0000-0002-1098-714X \\ Universidade Paulista, Brasil \\ E-mail: edumiyashita@icloud.com \\ Ivete Aparecida de Mattias Sartori \\ ORCID: https://orcid.org/0000-0003-3928-9430 \\ Instituto Latino Americano de Pesquisa e Ensino Odontológico, Brasil \\ E-mail: ivetemsartori@gmail.com \\ Andréia Aparecida Traina \\ ORCID: https://orcid.org/0000-0001-9193-1027 \\ Universidade de São Paulo, Brasil \\ E-mail: aatraina@usp.br \\ Flávio Domingues das Neves \\ ORCID: https://orcid.org/0000-0002-8676-302X \\ Universidade Federal de Uberlândia, Brasil \\ E-mail: flaviodominguesneves@gmail.com \\ Horacio D'Aguiar Silva Belo \\ ORICD: https://orcid.org/0000-0003-1744-0363 \\ Universidade de São Paulo, Brasil \\ E-mail: horaciobeloodontologia@gmail.com \\ Luis Ferreira de Almeida Neto \\ ORCID: https://orcid.org/0000-0003-3141-1227 \\ Universidade Federal do Rio Grande do Norte, Brasil \\ E-mail: luisneto_w@hotmail.com \\ Karolina Pires Marcelino \\ ORCID: https://orcid.org/0000-0002-2301-5155 \\ Universidade Federal do Rio Grande do Norte, Brasil \\ E-mail: karolpiresm@gmail.com \\ Ivalter José Ferreira \\ ORCID: https://orcid.org/0000-0002-0734-0812 \\ Universidade Federal do Rio Grande do Norte, Brasil \\ E-mail: ivalterjose@gmail.com \\ Marta Gonzalez Riesco \\ ORCID: https://orcid.org/0000-0002-9264-3075 \\ Universidade de São Paulo, Brasil \\ E-mail: mriesco2@uol.com.br
}

\begin{abstract}
Resumo
Introdução: O planejamento prévio, se faz extremamente necessário antes de qualquer intervenção reabilitadora, e quando associado aos avanços tecnológicos, tornam os resultados clínicos mais seguros e estáveis. Com a utilização dos exames de imagens digitais, incluindo radiografias, tomografias e imagem de escaneamento intraoral ou de modelos, pode-se dispor de imagens tridimensionais de toda estrutura óssea e gengival, que associado a um protocolo fotográfico, modelos de estudo e enceramento diagnóstico, resultam num impacto decisivo na sequência clínica da reabilitação oral. Objetivo: Este trabalho tem como objetivo discutir um caso de reabilitação interdisciplinar e complexa do sorriso. Relato de Caso: Paciente com agenesia dos elementos dentários 32 e 42 que foi reabilitada com implantes e laminados cerâmicos, onde a partir do diagnóstico e planejamento interdiscilplinar, construiu-se uma sequência de etapas passando pela ortodontia, periodontia, implantodontia e prótese consecutivamente até a reabilitação final. Conclusão: Conclui-se que o anseio pelos resultados estéticos é cada vez maior e casos com graves defeitos estéticos na arquitetura óssea e gengival, tornam um desafio na reabilitação oral. Técnicas reconstrututivas aliadas ao planejamento e execução integrada de especialidades são a chave para o sucesso do tratamento de casos
\end{abstract}


complexos. Grandes avanços no âmbito da tecnologia CAD/CAM, permitem executar a simulação virtual da reabilitação oral, tanto para as etapas cirúrgicas com a instalação de implantes osseointegráveis, como também para a reabilitação protética.

Palavras-chave: Implantes dentários; Ortodontia; Periodontia; Prótese dentária; Cirurgia bucal.

\begin{abstract}
Introduction: Prior planning is extremely necessary before any rehabilitation intervention, and when associated with technological advances, make clinical results safer and more stable. With the use of digital imaging exams, including radiographs, tomographies and intraoral scanning images or models, three-dimensional images of the entire bone and gingival structure can be made available, which associated with a photographic protocol, study models and diagnostic waxing, result in a decisive impact on the clinical sequence of oral rehabilitation. Objective: This paper aims to discuss a case of interdisciplinary and complex smile rehabilitation. Case Report: Patient with agenesis of dental elements 32 and 42 who was rehabilitated with implants and ceramic veneers, where from the diagnosis and interdisciplinary planning, a sequence of steps was constructed going through orthodontics, periodontics, implantology and prosthesis consecutively until the final rehabilitation. Conclusion: It is concluded that the yearning for aesthetic results is increasing and cases with severe aesthetic defects in bone and gingival architecture make it a challenge in oral rehabilitation. Reconstructive techniques combined with integrated planning and execution of specialties are the key to successful treatment of complex cases. Great advances in the field of CAD / CAM technology, allow to perform the virtual simulation of oral rehabilitation, both for the surgical stages with the installation of osseointegrated implants, as well as for prosthetic rehabilitation.
\end{abstract}

Keywords: Dental implants; Orthodontics; Periodontics; Prosthodontics; Oral surgery.

\title{
Resumen
}

Introducción: La planificación previa es extremadamente necesaria antes de cualquier intervención de rehabilitación, y cuando se asocia a avances tecnológicos, hace que los resultados clínicos sean más seguros y estables. Con el uso de exámenes de imágenes digitales, que incluyen radiografías, tomografías e imágenes o modelos de escaneo intraoral, se pueden poner a disposición imágenes tridimensionales de toda la estructura ósea y gingival, que se asocian con un protocolo fotográfico, modelos de estudio y encerado de diagnóstico. resultar en un impacto decisivo en la secuencia clínica de la rehabilitación oral. Objetivo: Este artículo tiene como objetivo discutir un caso de rehabilitación interdisciplinar y compleja de la sonrisa. Caso clínico: Paciente con agenesia de elementos dentarios 32 y 42 que fue rehabilitado con implantes y carillas cerámicas, donde a partir del diagnóstico y planificación interdisciplinar se construyó una secuencia de pasos, pasando por ortodoncia, periodoncia, implantología y prótesis de forma consecutiva hasta la rehabilitación final. Conclusión: Se concluye que el anhelo por resultados estéticos es cada vez mayor y los casos con severos defectos estéticos en la arquitectura ósea y gingival lo convierten en un desafío en la rehabilitación oral. Las técnicas reconstructivas combinadas con la planificación y ejecución integradas de especialidades son la clave para el tratamiento exitoso de casos complejos. Grandes avances en el campo de la tecnología CAD/CAM, permiten realizar la simulación virtual de rehabilitación oral, tanto para las etapas quirúrgicas con la instalación de implantes osteointegrados, como para la rehabilitación protésica.

Palabras clave: Implantes dentales; Ortodoncia; Periodoncia; Prostodoncia; Cirugía bucal.

\section{Introdução}

A reabilitação através dos implantes dentários vem cada vez mais sendo utilizada no tratamento de ausências dentárias totais e parciais para suprir as necessidades funcionais e/ou estéticas (Lewis, 1995; Da Silva et al., 2020; Silva et.al, 2020). Estas reabilitações constituem um desafio cada vez maior aos profissionais da área de reabilitação oral, pois o nível de exigência estética dos pacientes é crescente, desta forma é necessário a integração entre diferentes especialidades da área da odontologia visando otimizar os procedimentos e a previsibilidade do tratamento, estas interações interdisciplinares são a chave para melhorar os resultados estéticos principalmente em regiões anteriores de mandíbula e maxila (Loiola et al., 2016; Dias, de Souza, da Silva \& Menezes Filho, 2018; Medeiros et al., 2020).

O sucesso da implantodontia na atualidade há muito deixou de ser apenas a manutenção dos implantes no arco dentário, mas sim, todo um funcionamento harmônico do elemento artificial que inclui a dinâmica oclusal, uma estética coerente e conforto ao paciente. Não é menos verdade que a interação multidisciplinar num tratamento reabilitador tão abrangente como é, através de implantes, merece uma atuação efetiva e bem embasada, seguindo, portanto, o mapa do planejamento programado (Carvalho, 2006; El Askary, 2001; Loiola et al., 2016; Medeiros et al., 2020; Da Silva et al., 2020).

A realização do tratamento ortodôntico anteriormente à instalação de implantes tem por finalidade a obtenção de uma 
oclusão aceitável, possibilitar condições de higienização, estabelecer um tratamento estável e espaço protético adequado para a futurareabilitação protética (Lewis, 1995; Garber \& Belser, 1995; Souza et al., 2016). Com relação à periodontia, o emprego de técnicas cirúrgicas periodontais é capaz de modificar um biótipo fino em espesso, aumentando a previsibilidade dos resultados dos tratamentos protéticos e a satisfação do paciente (Garber \& Belser, 1995). Quanto ao restabelecimento protético, o grande desafio atual é conseguir a relação ideal entre a coroa protética e os tecidos circunvizinhos, atingir beleza e contorno natural da gengiva em volta do implante ainda é, e sempre será desafiador por envolver diversas variáveis técnicas e biológicas (Garber \& Belser, 1995; Carvalho, 2006).

Em casos de agenesia ou ausência por perda dentária, ocorre a remodelação do rebordo alveolar e a perda de volume periodontal, interferindo na estética periimplantar (Beyer, Tausche, Boening \& Harzer, 2007). Quando há remodelação de rebordo alveolar, dentes vizinhos geralmente são afetados, perdendo estrutura óssea nas regiões adjacentes à perda dentária, causando recessão gengival e trazendo complicações como: hipersensibilidade dentinária, cáries radiculares, desenvolvimento de abrasões cervicais, além de comprometer a estética. $\mathrm{O}$ uso da técnica cirúrgica de recobrimento gengival utilizando retalho deslocado coronalmente ou lateralmente, associado ou não a enxerto de tecido conjuntivo subepitelial se mostra muito eficiente para esses casos (Da Silva Feitosa et al., 2008).

As recessões gengivais, múltiplas ou isoladas, também podem ser solucionadas através da técnica de enxerto gengival livre, além do aumento em espessura da gengiva queratinizada. A quantidade e qualidade dos tecidos periimplantares, o contorno gengival são um desafio, uma vez que se estabelece a involução do osso alveolar (Da Silva Feitosa et al., 2008). Em reabilitação com implantes dentários, devemos fazer cirurgia em sítios onde se encontra gengiva queratinizada. Nos casos em que não há disponibilidade de tecido queratinizado, apresentando no sítio cirúrgico apenas mucosa alveolar, não é possível realizar a técnica cirúrgica de instalação do implante dentário. Indica-se o enxerto gengival livre para casos de ausência de gengiva queratinizada, inflamação persistente dos tecidos moles periimplantares ou casos de vestíbulo insuficiente abaixo de overdentures (Borguetti \& Monnet-Corti, 2002).

Desta forma, este trabalho objetiva descrever, através de um relato de caso, a possibilidade da resolução estética em área de difícil reabilitação, utilizando um planejamento multidisciplinar, com abordagem ortodôntica, periodontal, implantar e protética, assim como a eleição das técnicas cirúrgicas adequadas para o caso, chamando a atenção para o exame clínico minucioso e planejamento em conjunto.

\section{Metodologia}

Este trabalho trata-se de um estudo de caso, descritivo e qualitativo. De acordo com Pereira, Shitsuka, Parreira e Shitsuka (2018) este tipo de estudo refere-se a uma descrição de uma temática específica, esmiuçando-a para evidenciar suas particularidades e qualificar sua relevância. No trabalho em questão, evidencia-se uma reabilitação oral implantossuportada através de um tratamento interdisciplinar associando diversas áreas do conhecimento como a periodontia, ortodontia, implantodontia e prótese dentária. Em relação aos aspectos éticos, foram fornecidas informações a paciente por meio do Termo de Consentimento Livre e Esclarecido (TCLE) e a autorização do procedimento ocorreu mediante assinatura deste documento.

\section{Relato de Caso}

Paciente do gênero feminino, 30 anos, procurou tratamento na Fundecto-USP (Fundação Faculdade de Odontologia conveniada à FOUSP) com queixa de ausência dentária na região dos elementos 32 e 42, além de queixa estética na região anterior. 
Ao exame clínico inicial, disponível na Figura 1, observou-se ausência dentária dos elementos 32 e 42 com espaço mésio-distal reduzido para reposição dos elementos 32 e 42. Observa-se também, depressão acentuada na região vestibular dos elementos ausentes, faixa estreita de mucosa queratinizada e biótipo gengival fino. Para análise detalhada do caso, foi solicitada documentação ortodôntica completa e solicitação de tomografia computadorizada. A análise facial foi realizada para observação da dimensão vertical, suporte de lábio, proporção facial e a exposição de incisivo superior em repouso e sorriso espontâneo.

Figura 1 - Imagens iniciais da paciente. A: oclusão inicial; B: região anterior da mandíbula, evidenciando a ausência dos elementos dentários 32 e 42.

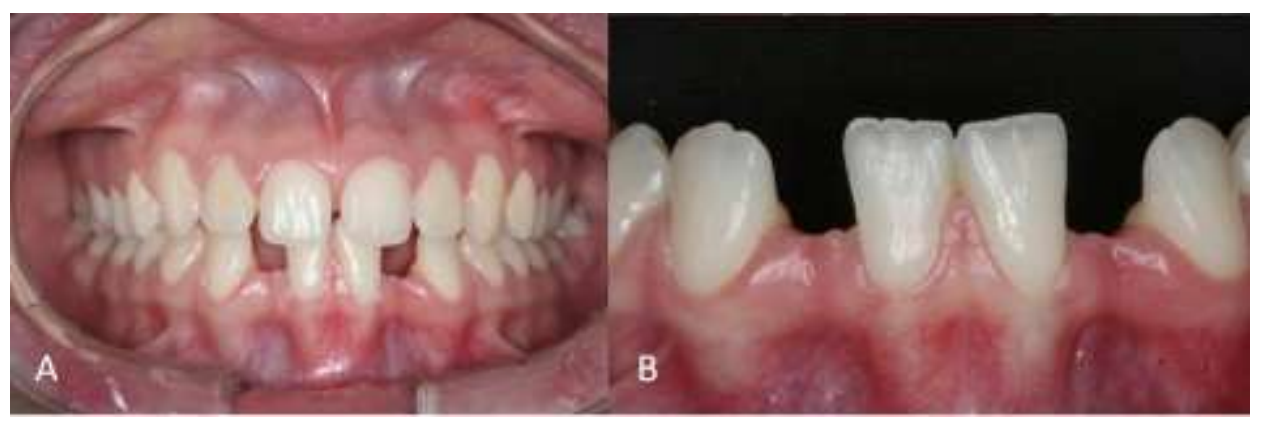

Fonte: Autores (2021).

Em virtude da agenesia dos incisivos laterais inferiores, apresentando uma arquitetura óssea pobre e impossibilitando a realização de implantes no local, optou-se por substituir ortodonticamente os incisivos laterais ausentes pelos centrais, deixando o osso da região central adequada para a realização dos implantes. Assim, a movimentação ortodôntica dos centrais para a região dos laterais, "induziu” uma neoformação óssea. Este procedimento é extremamente delicado, e requer bastante cuidado no planejamento. Foram aplicadas forças suaves e os movimentos lentos, respeitando a resposta óssea e gengival. A seleção de fios e ativações do aparelho, deve ser realizada criteriosamente, para não provocar movimentos pendulares ou de vai e vem (no sentido mésio-distal e vestíbulo-lingual), ou rotações, que podem provocar uma reabsorção radicular e danificar a já delicada estrutura óssea e gengival. Foi empregado um aparelho de baixo-atrito de molar a molar, que favorece o uso de forças de ativação extremamente leves, muito necessárias neste caso.

Inicialmente procedeu-se o alinhamento e nivelamento de todos os dentes inferiores, para que pudessem receber um fio bem resistente com controle tridimensional dos movimentos, que ao mesmo tempo "guiasse" os incisivos para sua nova posição e evitasse os movimentos indesejáveis. Os dentes posteriores serviram de apoio para a distalização dos incisivos. Ao final da distalização, observa-se ganho de espaço mésio-distal para instalação de implantes nas regiões do 31 e 41 . Os dentes distalizados que agora ocupam a região do 32 e 42, serão assim chamados para facilitar o entendimento. Apesar de toda cautela na condução ortodôntica, os elementos 32 e 42 apresentaram importante recessão gengival, devido ao biotipo gengival fino e ínfima faixa de mucosa ceratinizada na região do arco gengival, como também, estreita faixa de gengiva na região do 31 e 41 , como pode ser visto na Figura 2. 
Figura 2 - Foto frontal intraoral após movimentação ortodôntica evidenciando recessão gengival acentuada nos incisivos 32 e 42.

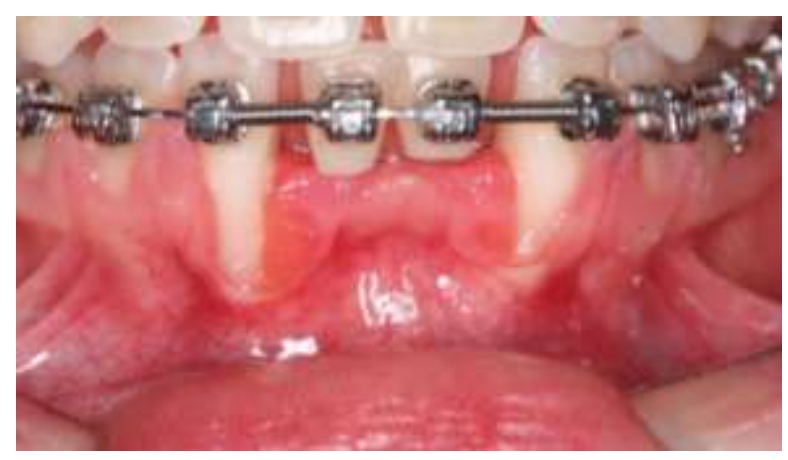

Fonte: Autores (2021).

Com o objetivo de manter os elementos 32 e 42 e melhorar o prognóstico na área edêntula, optou-se por fazer o enxerto gengival livre do 32 ao 42, para recobrimento radicular e ganho de mucosa ceratinizada, visualizado na Figura 3. A técnica utilizada foi de enxerto autógeno com área doadora do palato e o leito receptor sendo preparado através de retalho dividido, desde a linha de união muco gengival com duas incisões relaxantes nas distais de 32 e 42 . Após seguimento de 90 dias de pós operatório, foi observado o ganho de mucosa ceratinizada por toda a extensão da área enxertada, com ganho de volume, alteração do biótipo e recobrimento radicular parcial.

Figura 3 - Enxerto gengival livre. A: retalho dividido do 32 a 42; B: enxerto gengival livre suturado ao leito receptor; C: área doadora do enxerto (palato); D: pós operatório de 90 dias, mostrando o ganho de mucosa queratinizada, entretanto a recessão persistente no 32 e 42 .

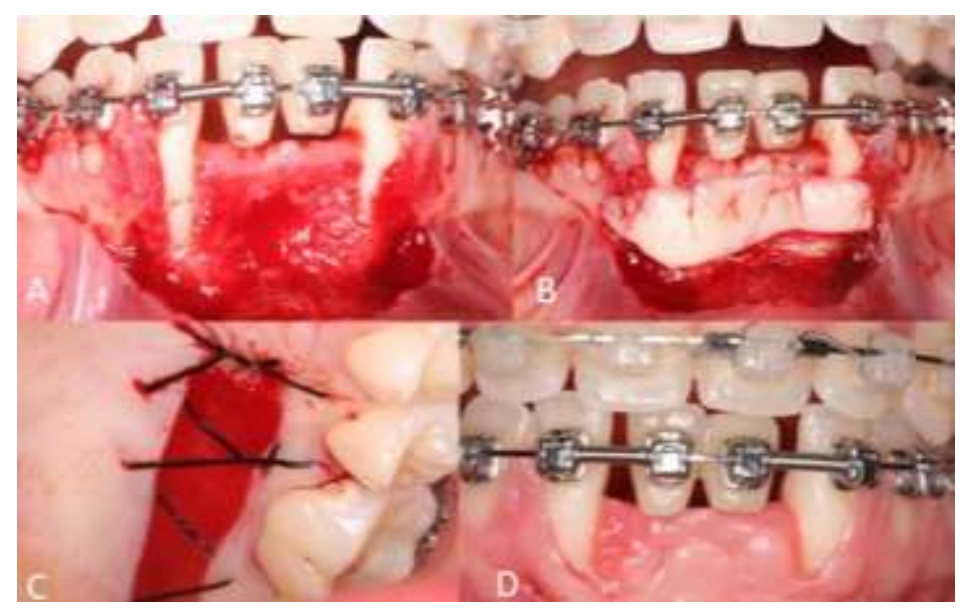

Fonte: Autores (2021).

Após 90 dias do enxerto gengival livre, ainda é possível observar recessão gengival moderada nos dentes 32 e 42 . Com intuito de melhorar a estabilidade desses elementos, higiene e controle de placa, optou-se por novo recobrimento radicular. Em virtude da qualidade e quantidade de mucosa queratinizada alcançada na técnica anterior, foi escolhida a técnica do deslize lateral permitindo o deslize com segurança e previsibilidade.

O deslize lateral, ilustrado na Figura 4, foi realizado através de incisão em crista do rebordo, retalho dividido e duas incisões relaxantes centrais, uma para cada lado, a fim de criar o retalho para deslize. As margens do dos arcos gengivais do 32 e 42 foram desepitelizadas para receber e nutrir os retalhos criados na área central e deslizados lateralmente para recobrir as raízes do 32 e 42 . As áreas centrais ficaram cobertas por periósteo e com margens desepitelizadas em mucosa queratinizada. 
Após 90 dias de acompanhamento pós-operatório, observou-se excelente recobrimento radicular do elemento 32, com bom resultado estético e melhora satisfatória no recobrimento radicular do elemento 42.

Figura 4 - Técnica do deslize lateral para recobrimento radicular. A: aspecto inicial; B: retalho deslizado para região das recessões dos elementos dentários 32 e 42; C: pós-operatório de 90 dias.

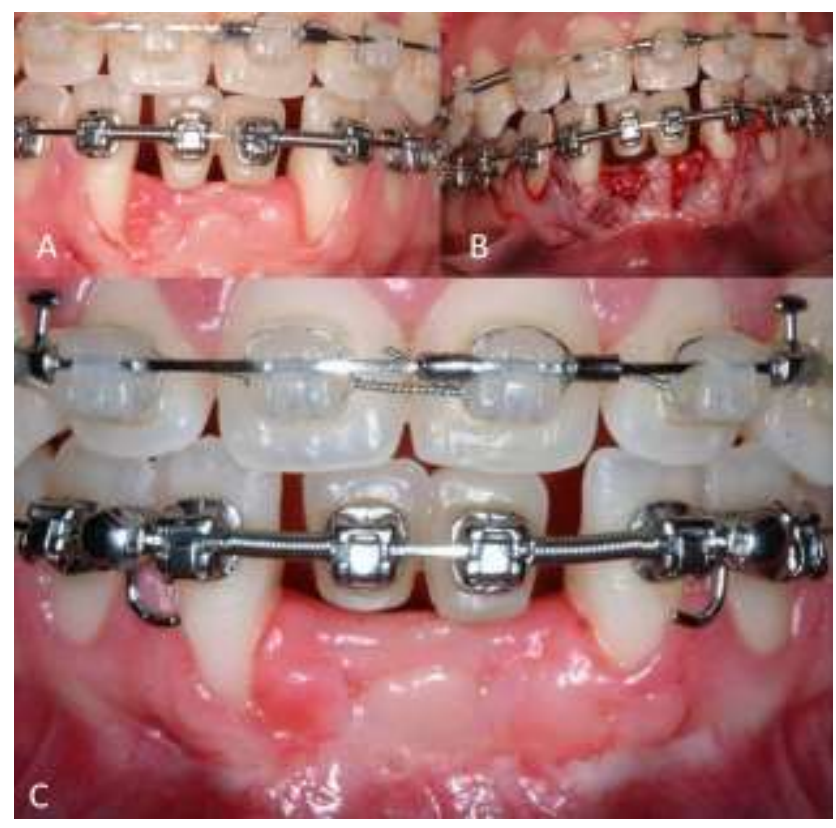

Fonte: Autores (2021).

Por tratar-se de um caso com alta demanda estética e requerer o máximo de estabilidade do tratamento, optou-se por uma nova cirurgia de recobrimento radicular na região do elemento 42, dessa vez associando o deslize lateral com enxerto de conjuntivo, na Figura 5. Foi removido enxerto de tecido conjuntivo do palato, realizado retalho parcial com relaxante na porção central do espaço do 31 e 41 para permitir a rotação dele. O tecido conjuntivo foi inserido na vestibular da recessão do 42 e recoberto pelo retalho rotacionado lateralmente. Após 90 dias de acompanhamento pós-operatório, foi alcançado o perfil gengival adequado e assim dado seguimento ao planejamento da reabilitação com implantes osseointegrados.

Figura 5 - Técnica do deslize lateral associado ao enxerto de conjuntivo no elemento 42. A: situação inicial; B: interposição do tecido conjuntivo; C: retalho reposicionado em posição; D: pós-operatório de 90 dias.

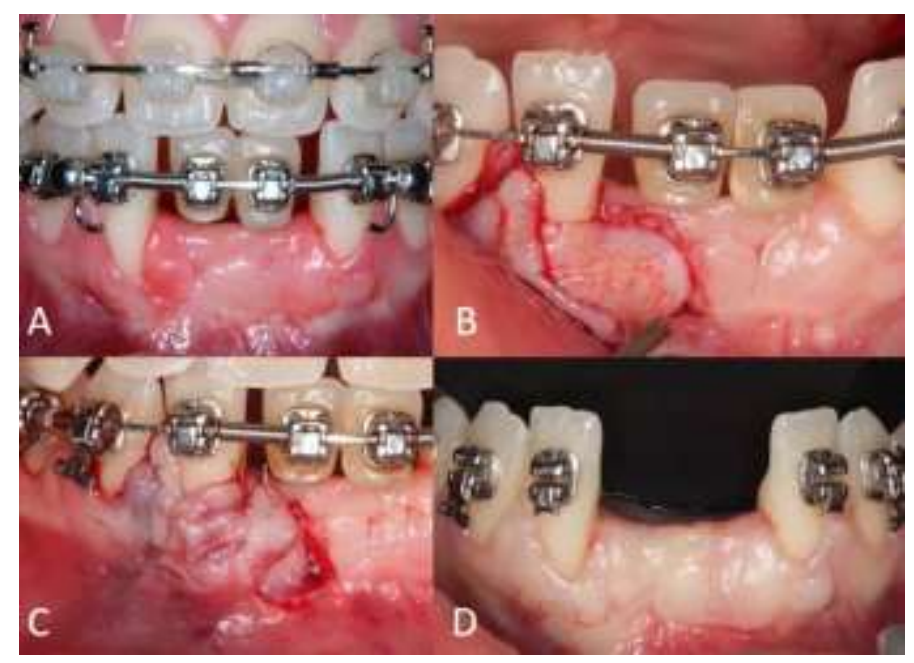

Fonte: Autores (2021). 
Foram planejados dois implantes estreitos 3.0x11,5mm (Nobel active) em virtude de tratar-se de incisivos inferiores e pouca disponibilidade óssea. A incisão foi realizada sem envolver as papilas dos elementos 32 e 42 , a fim de evitar possíveis retrações nessas áreas. Realizou-se um retalho trapezoidal com descolamento delicado do periósteo, a crista óssea extremamente fina foi removida com auxílio de alveolótomo biarticulado e aplainada com auxílio de limas para osso, imagens disponíveis na Figura 6.

Figura 6 - Preparo do leito para instalação dos implantes. A: incisão trapezoidal evitando as papilas; B: vista frontal, após descolamento subperiosteal; C: vista oclusal da crista alveolar extremamente fina; D: após remoção da crista óssea.

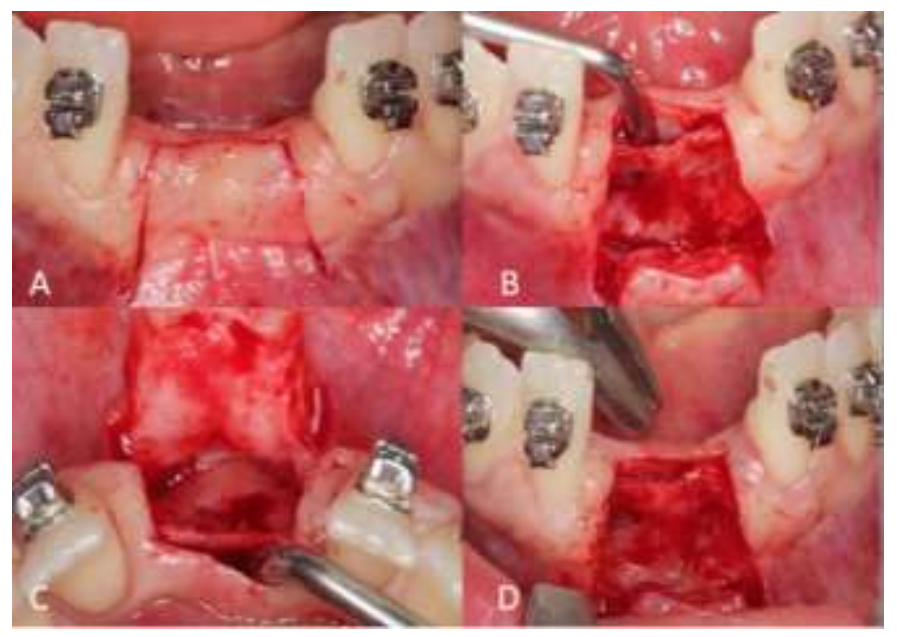

Fonte: Autores (2021).

Com auxílio de guia cirúrgico confeccionado em resina acrílica prensada em laboratório e adaptado sobre as oclusais dos elementos vizinhos, foi realizada a instrumentação do leito seguindo a sequência de brocas preconizada pelo fabricante para instalação dos implantes. Após a fresagem completa dos alvéolos, os implantes foram inseridos com auxílio de contra ângulo e finalizados com chave catraca respeitando o torque máximo preconizado pelo fabricante de $35 \mathrm{~N} / \mathrm{cm}^{3}$. Com objetivo de condicionamento gengival, selecionamos um pilar temporário (Immediate temporary abutment - Nobel) para provisionalização imediata. O pilar temporário foi instalado utilizando o torque máximo preconizado pelo fabricante de 15 N/cm ${ }^{3}$, sequência que pode ser observada na Figura 7. 
Figura 7 - Instalação dos implantes dentários. A: guia cirúrgico em posição; B: início da fresagem com o guia em posição; C: paralelismo entre as perfurações; D: vista frontal das perfurações; E: implantes instalados; F: pilar temporário instalado para provisionalização imediata.

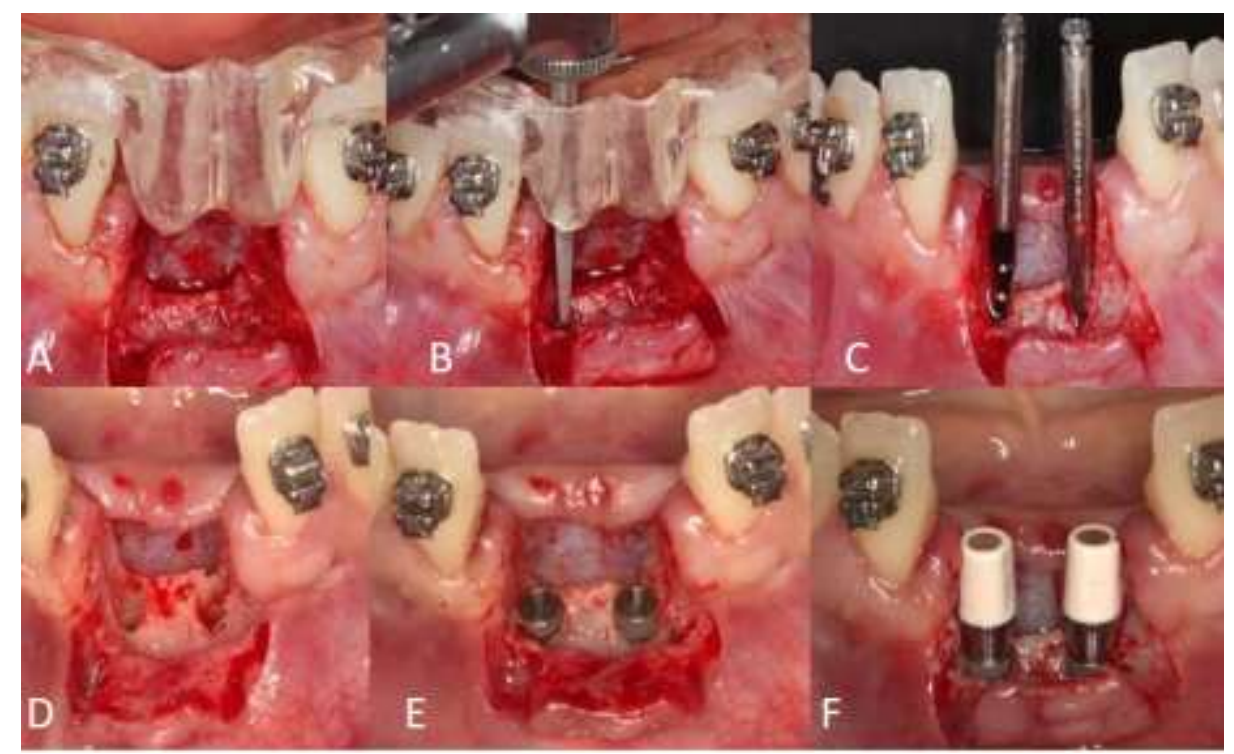

Fonte: Autores (2021).

Utilizando provisórios pré-confeccionados com base no planejamento, foram capturados em boca os cilindros provisórios com uso de resina acrílica (Alike - GC). Foi realizado o perfil de emergência desejado, dado acabamento e polimento no provisório com uso de borrachas e feltro, sendo a cimentação realizada com utilização de cimento de hidróxido de cálcio. O provisório foi instalado em infraoclusão isento de qualquer contato. Procedeu-se então a sutura do retalho vestibular recobrindo toda a porção cervical dos provisórios, com intuito de dar o máximo de recobrimento a esses dentes e assim alcançar um bom condicionamento gengival, sequência disponível na Figura 8.

Figura 8 - Provisionalização imediata. A: captura dos cilindros com os provisórios; B: imagem das coroas provisórias sem acabamento; C: acabamento e polimento; D: aspecto das coroas após o acabamento; E: cimentação temporária, evidenciando a infraoclusão das coroas provisórias; F: sutura suspensória.

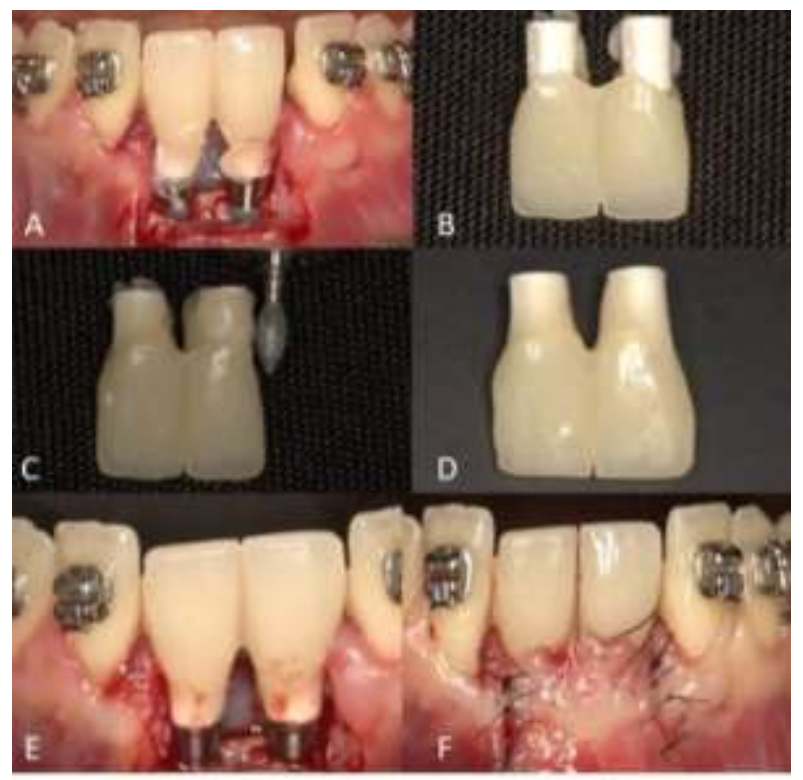

Fonte: Autores (2021). 
A paciente foi orientada a realizar higiene oral com escova extramacia e bochechos com clorexidina $0,12 \%$ durante o período de 30 dias, como também manter dieta pastosa e não apreender nunhum tipo de alimento com os incisivos. Após o período de osseointegração de 6 meses, foi realizada a remoção dos provisórios, na Figura 9.

Figura 9 - Aspecto clínico do pós-operatório de 6 meses após a instalação dos implantes.

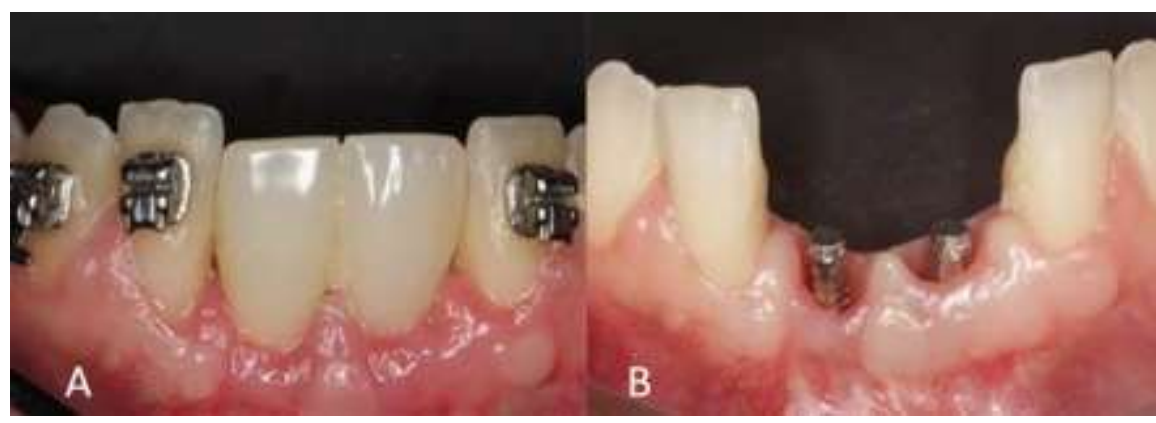

Fonte: Autores (2021).

Foi utilizada a técnica de individualização dos transferentes de moldagem, a fim de replicar o perfil de emergência obtido com os provisórios. Para isso, foi utilizada silicone de adição pesada e leve, com introdução dos provisórios adaptados aos análogos até a margem gengival. O espaço formado pelo perfil de emergência dos provisórios é então preenchido com resina acrílica ao redor dos transferentes de moldagem. É então realizada a instalação dos transferentes de moldagem nas cabeças dos implantes. Os transferentes de moldagem são unidos por resina acrílica (Pattern Resin LS - GC) para alcançar maior estabilidade e fidelidade na transferência da posição dos implantes. A técnica de eleição para esse caso é com moldeira aberta acrílica, aplicado o adesivo para silicona em toda a superfície da moldeira e utilizando siliconas pesada e leve em estágio único. São adaptados os análogos e o molde então é enviado ao laboratório de prótese para vazamento, sequência visualizada na Figura 10.

Figura 10 - Captura do perfil de emergência. A: adaptação do provisório ao análogo do pilar; B: moldagem do perfil de emergência; C: personalização do transferente de moldagem; D: união dos transferentes de moldagem; E: aplicação de adesivo na moldeira; F: moldagem com silicone de adição (pesada e leve).

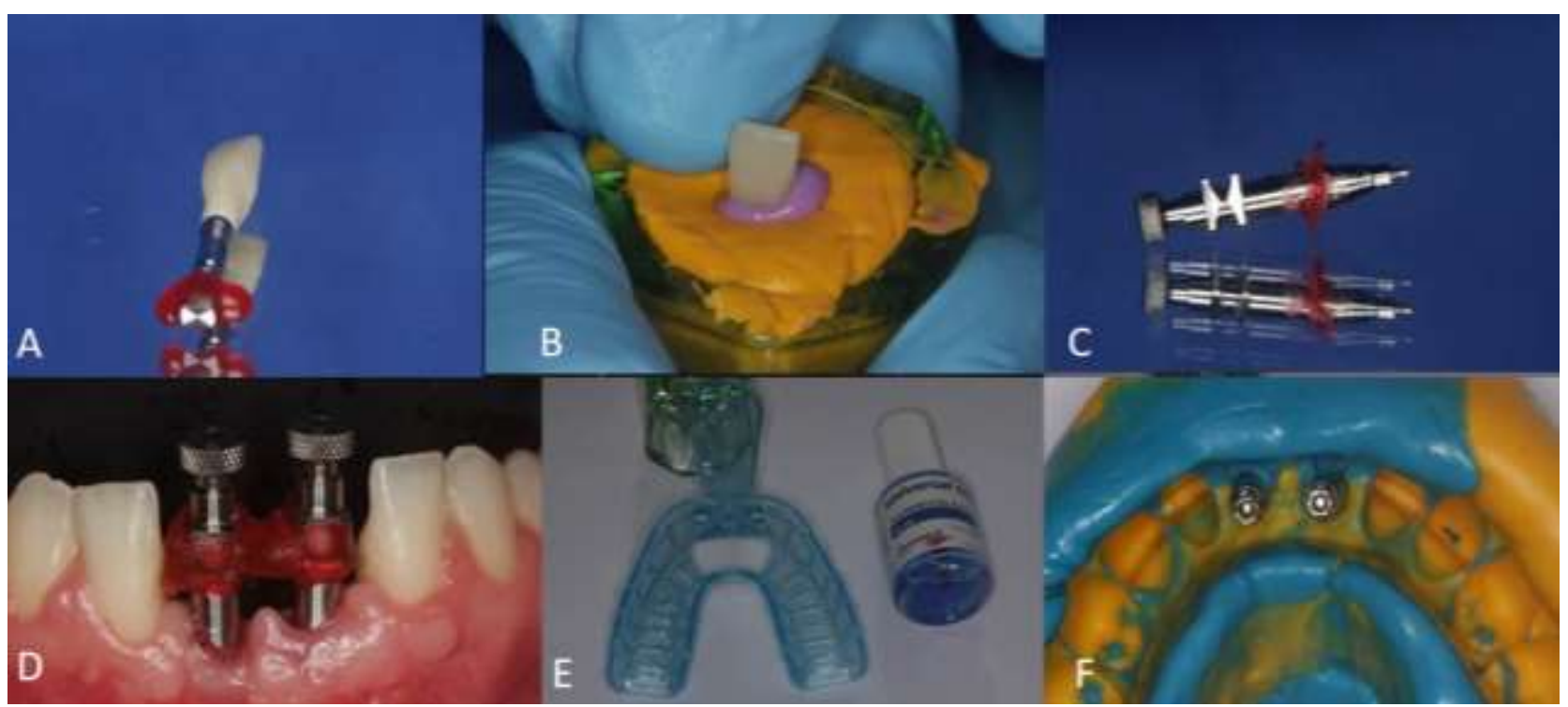

Fonte: Autores (2021). 
A anatomia complexa do caso em relação ao tecido ósseo, profundidade dos implantes instalados e dentes vizinhos, impossibilitou o uso de componentes protéticos pré fabricados na forma padrão da empresa (Nobel), o que nos levou a lançar mão do planejamento digital para individualização do caso. De posse do modelo físico, foram adaptados aos análogos dos implantes para escaneamento digital do modelo, com isso gerou-se um modelo virtual através de um arquivo STL (standard traingle language) para CAD-CAM (computer aided design and manufacturing) e os pilares para recebimento das futuras coroas foram desenhados virtualmente através do programa Zirkonzahn modelier (Zirkonzahn scan - software), fresados em resina e o projeto realizado no CAD da Zirkonzahn, foram enviados ao fabricante dos implantes (Nobel), para checagem do projeto e fresagem do pilares em titânio na Figura 11.

Figura 11 - Pilares protéticos desenhados virtualmente. A: modelo virtual, sendo verificado o paralelismo entre os implantes; B: análise dos pilares desenhados virtualmente; C: pilares fresados em titânio vista frontal; D: vista lingual dos pilares fresados.

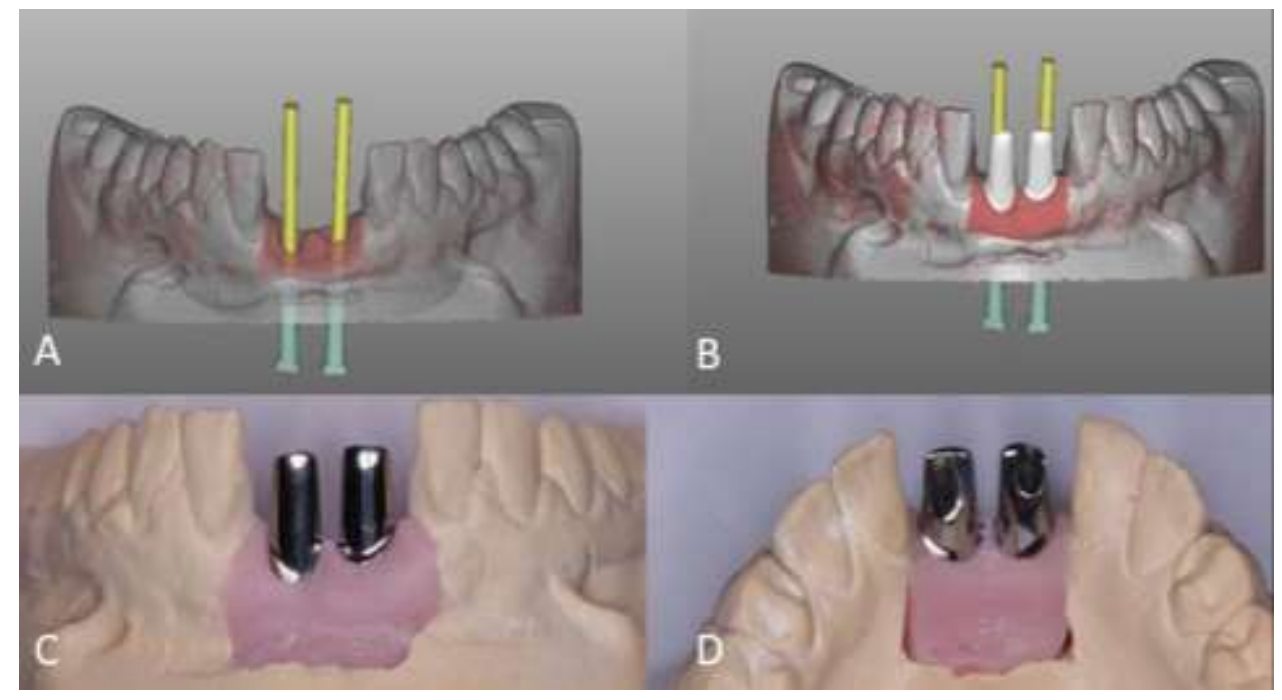

Fonte: Autores (2021).

Na Figura 12, observam-se os pilares foram instalados para prova em boca e as coroas fresadas em CAD/CAM. Na Figura 13, os pilares foram instalados, seguidos de acabamento no término cervical do preparo para melhor acomodação estética em relação a margem gengival. Os incisivos laterais (32 e 42) foram preparados para laminados cerâmicos para juntamente com as coroas cerâmicas sobre implante, darem melhor resultado estético, dando mais harmonia na forma e cor da restauração protética. As coroas cerâmicas sobre implante e os laminados cerâmicos sobre dentes foram cimentados com cimento resinoso dual. O ajuste oclusal e das guias oclusais foi realizado e paciente recebeu orientações de higiene e retorno para controle. Pode-se observar as imagens do tratamento finalizado na Figura 14, evidenciando a melhora da harmonia do sorriso e estética. As imagens do acompanhamento imaginológico encontram-se na Figura 15, na qual observa-se com 6 meses de pós-operatório os implantes estão osseointegrados, bem posicionados e boa condição periodontal dos elementos 31 e 41 , que ocupam a posição do 32 e 42 , respectivamente. 
Figura 12 - Pilares e coroas em cerâmica. A: Vista vestibular das coroas e facetas em cerâmica; B: Vista lingual das coroas e facetas em cerâmica; C: Coroas e facetas em cerâmica evidenciando a cor e translucidez; D: Prova dos pilares.

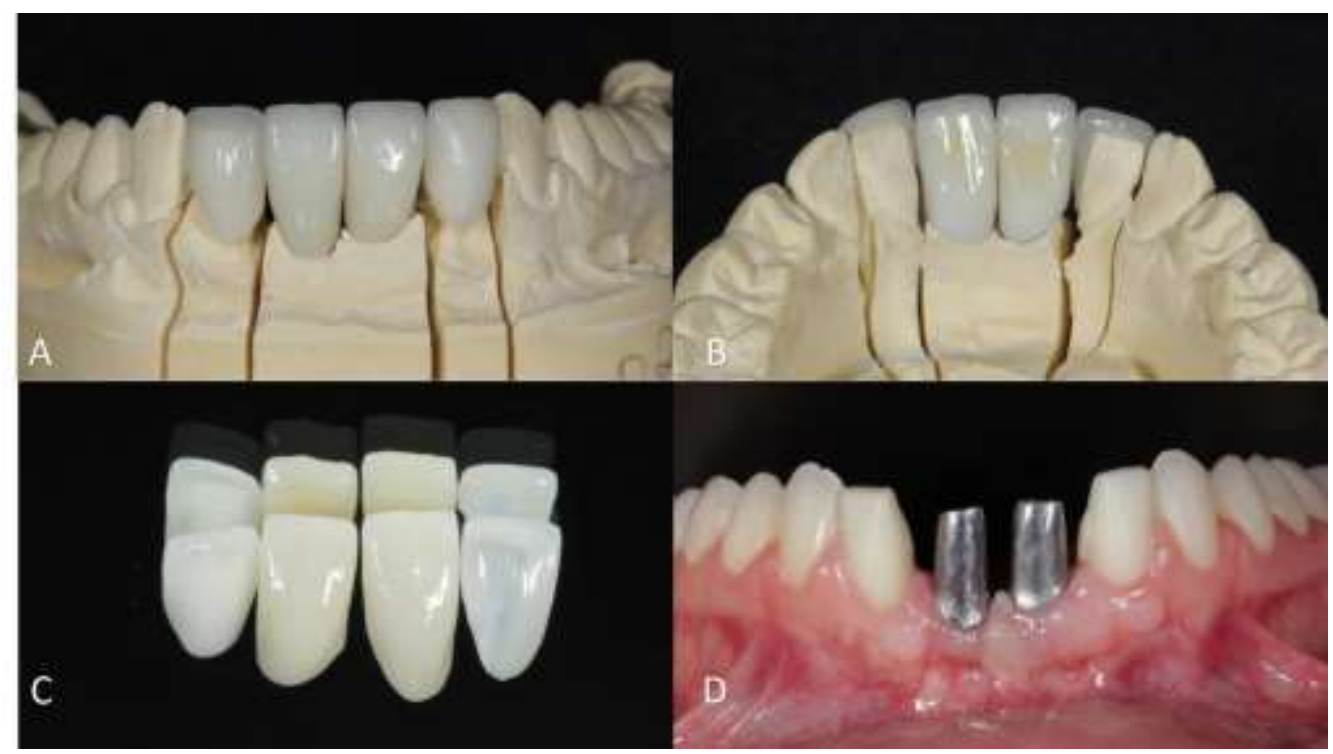

Fonte: Autores (2021).

Figura 13 - Finalização do caso. A: vista frontal da prova dos pilares; B: vista oclusal da prova dos pilares; C: prova das coroas definitivas sem acabamento e moldagem do 32 e 42 para confecção de laminados cerâmicos; D: Instalação das coroas definitivas e prova de cor para os laminados dos elementos 32 e 42 .

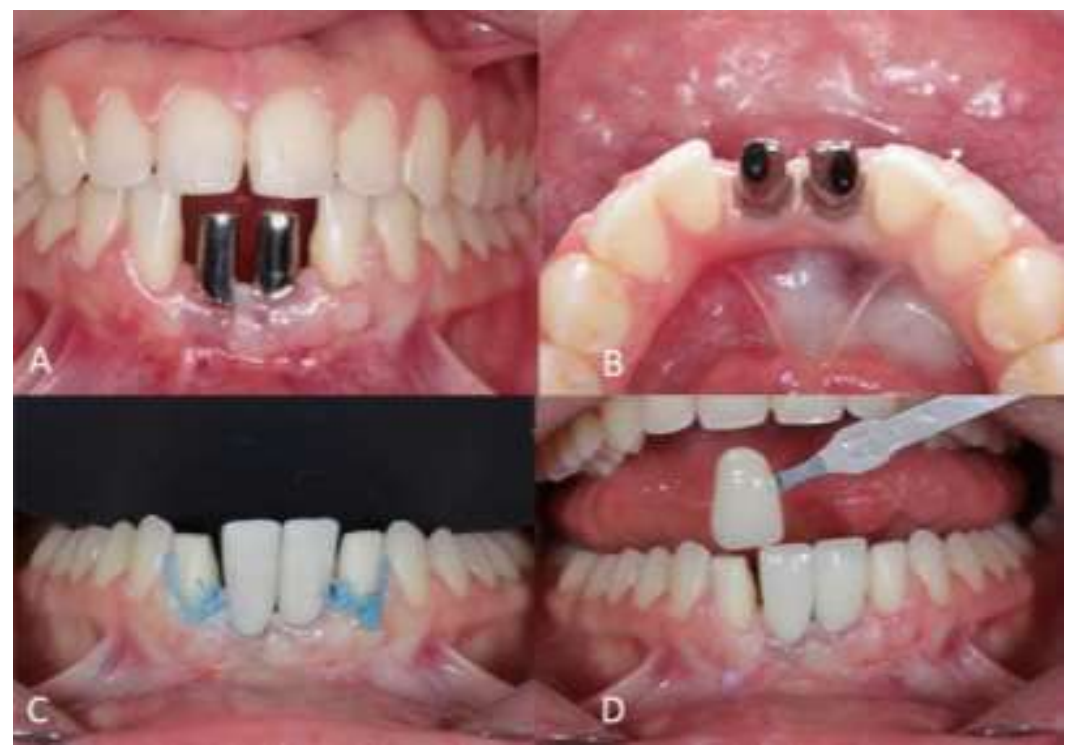

Fonte: Autores (2021). 
Figura 14 - Imagens da reabilitação finalizada. A: Vista frontal do sorriso com as coroas cimentadas. B: Vista da arcada inferior com ênfase na região reabilitada de 32 a 42 , com coroas e facetas cimentadas.

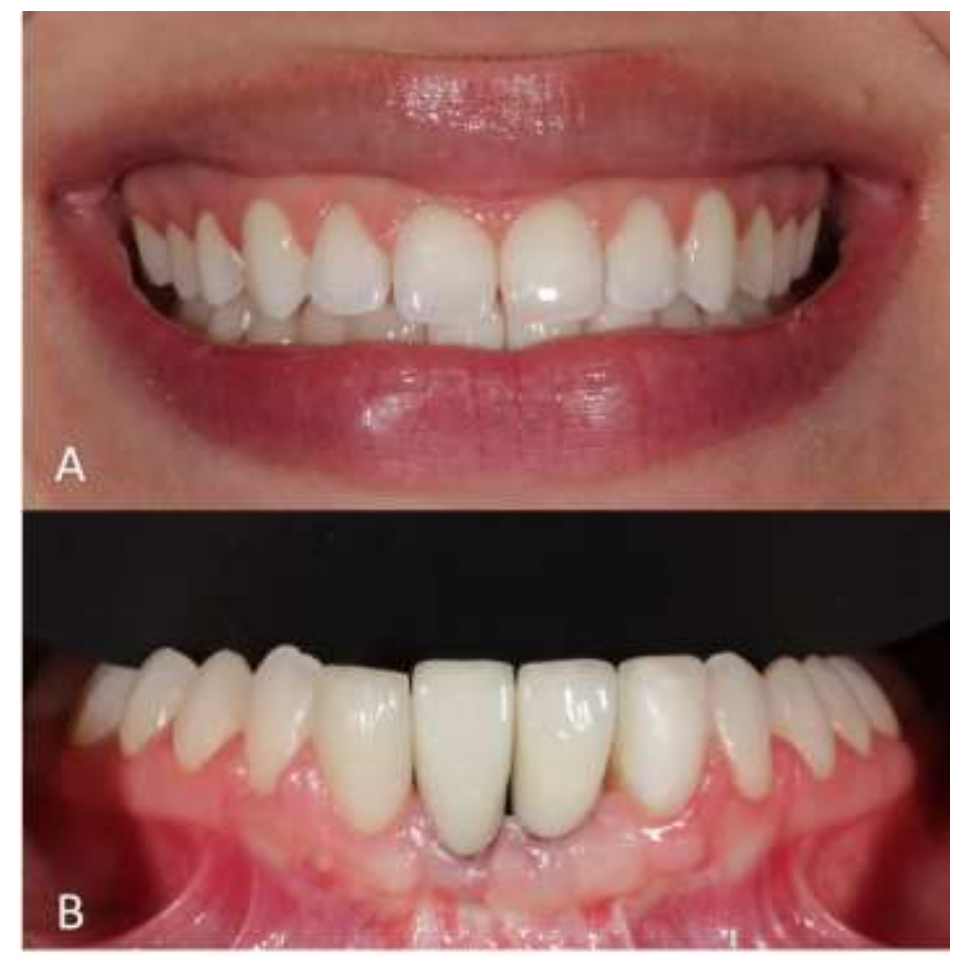

Fonte: Autores (2021).

Figura 15 - Aspecto tomográfico dos implantes após 6 meses da instalação.

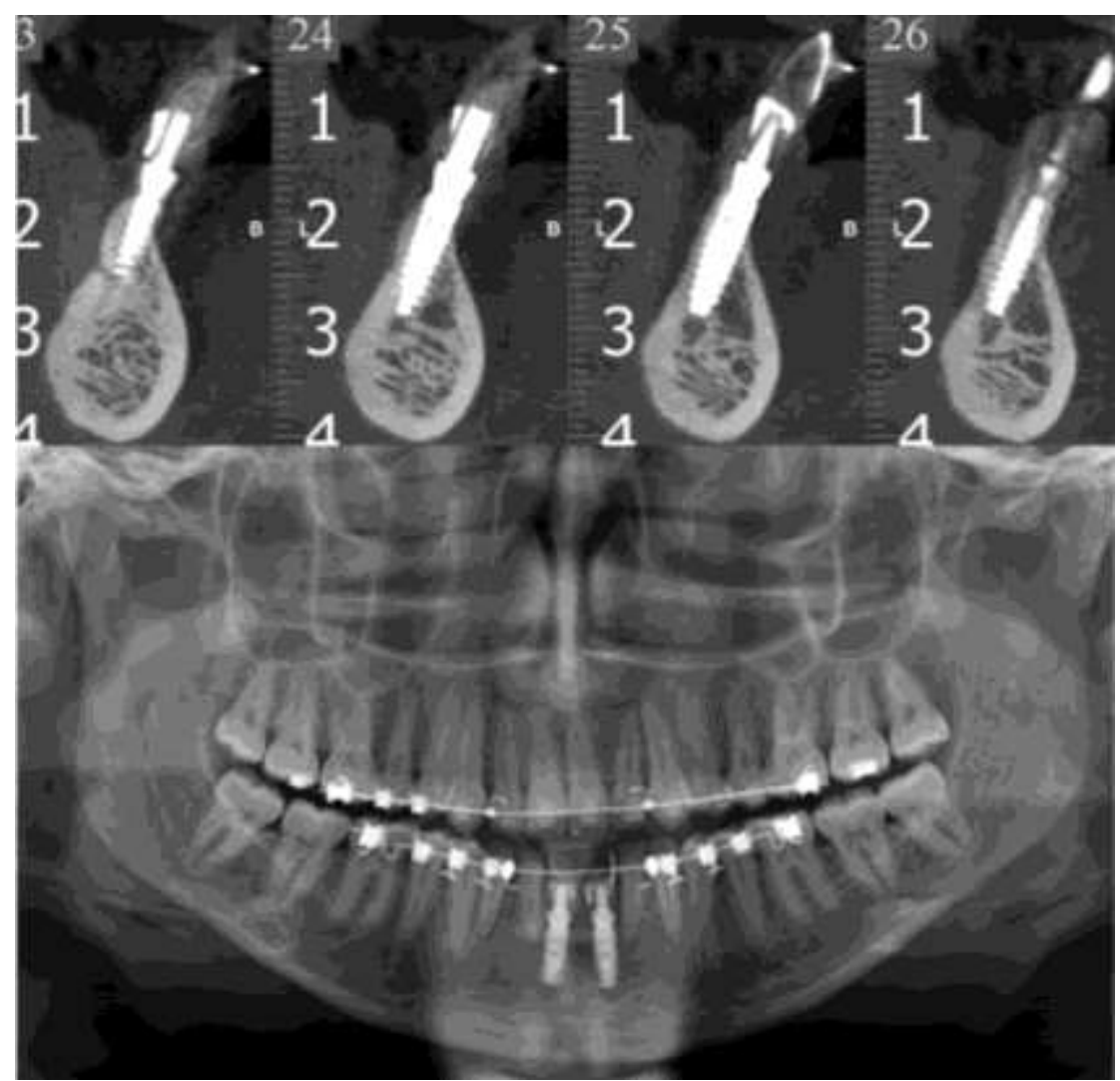

Fonte: Autores (2021). 


\section{Discussão}

Devido à falta de remanescente ósseo, os implantes foram instalados numa profundidade além dos padrões convencionais, tornando a área muito estreita para lançar mão de pilares padronizados de fábrica. Para uma adaptação ideal, planejamos utilizar um pilar confeccionado por CAD/CAM no Sistema Nobel PROCERA, com intuito de trabalhar com pilares originais e em titânio, com parâmetros corretos e melhor resposta biológica ao pilar.

Os laminados cerâmicos são aconselhados em situações extensas, especialmente quando envolve as incisais dos dentes anteriores. Eles permitem uma melhor adaptação do material restaurador nas regiões cervicais e proximais, além do refinamento da anatomia, por ser confeccionado em laboratório (Shenoy \& Shenoy, 2010; Da Cunha, Coesta, Da Escóssia \& Mondelli, 2013).

Para uma conformidade de cor, textura e correção de contornos, sugerimos a confecção de laminados cerâmicos para os dentes 32 e 42, a fim de finalizar o caso solucionando a estética anterior dos dentes inferiores. Esse tratamento deve ser conversado e planejado com o paciente, e deve ser monitorado por todos os profissionais envolvidos na reabilitação (Da Cunha, Mondelli \& Furuse, 2011).

Os laminados cerâmicos, sempre que possível, devem ser utilizados de forma associada aos tratamentos ortodôntico, periodontal, protéticos e implantares, estabelecendo a estética e a função dos dentes anteriores.

\section{Considerações Finais}

A abordagem interdisciplinar é o ponto chave do sucesso de um tratamento reabilitador. Tão importante quanto o diagnóstico, é planejar, de forma eficaz a execução do caso, proporcionando ao paciente um tratamento mais preciso e estável a longo prazo, aliando a função e a estética. O uso da tecnologia CAD-CAM é essencial para a resolução de casos complexos de prótese sobre implante, tornando possível a adequação biomecânica e estética de casos onde a anatomia é desfavorável.

\section{Referências}

André, L. F. M., Luppino, T. A., Amaral, J. M. B. L. D., \& Santos, T. M. D. (2005). Otimizando a estética final de uma prótese unitária anterior utilizando o condicionamento gengival e pilar de zircônia: relato de caso clínico. ImplantNews, 623-628.

Antoniazzi, M. C. C., Castilho, J. D. M., Moraes, L. C. D., \& Medici Filho, E. (2013). Estudo da prevalência de anodontia de incisivos laterais e segundos prémolares em leucodermas brasileiros, pelo método radiográfico. Revista de Odontologia da UNESP, 28(1), $177-185$.

Beyer, A., Tausche, E., Boening, K., \& Harzer, W. (2007). Orthodontic Space Opening in Patients with Congenitally Missing Lateral IncisorsTiming of Orthodontic Treatment and Implant Insertion. The Angle Orthodontist, 77(3), 404-409.

Borguetti, A., \& Monnet-Corti, V. (2002). Cirurgia plástica periodontal. Artmed.

Carvalho, P. (2006). Planejamento cirúrgico protético em implantodontia. Rev Inovations Journal, 37(4), 12-8.

Da Cunha, L. F., Coesta, P. T. G., da Escóssia Jr, J., \& Mondelli, J. (2013). Interrelação Periodontia e Dentística Restauradora na lapidação de facetas cerâmicas.

Da Cunha, L. F., Mondelli, J., \& Furuse, A. Y. (2011). Planejamento e considerações pré e pós-operatórias no fechamento de diastemas. Revista Brasileira de Odontologia, 68(1), 12.

Da Silva, R. A. R., de Almeida Neto, L. F., Marcelino, K. P., Cardoso, L. C. L., Dantas, E. M., Barbosa, G. A. S., \& Gondim, A. L. M. F. (2020). Osteotomia segmentar da maxila em área estética para viabilizar reabilitação com implantes dentários: relato de caso. Research, Society and Development, 9(9), e594997525-e594997525.

Da Silva Feitosa, D., Santamaria, M. P., Sallum, E. A., Junior, F. H. N., Casati, M. Z., \& de Toledo, S. (2008). Indicações atuais dos enxertos gengivais livres. $R G O, 56(2), 1-6$.

Dias, M. F., de Souza, P. C. B. V., da Silva, C. H. V., \& Menezes Filho, P. F. (2018). Implantodontia, dentística, periodontia e ortodontia aliadas na reabilitação estético-funcional após trauma dental provocado por acidente automobilístico: relato de caso. Archives Of Health Investigation, 7.

El Askary, A. E. S. (2001). Multifaceted aspects of implant esthetics: the anterior maxilla. Implant dentistry, 10(3), $182-191$. 
Research, Society and Development, v. 10, n. 1, e16310111565, 2021

(CC BY 4.0) | ISSN 2525-3409 | DOI: http://dx.doi.org/10.33448/rsd-v10i1.11565

Figueiredo, C. M., Dias, R. P., Monteiro-Amado, F., Rossi, F. C. C., Colombini-Ishikiriama, B. L., Oliveira, T. M., \& Santos, C. F. D. (2011). O uso de implantes, enxerto ósseo e condicionamento do tecido gengival perimplantar na reabilitação estética de área anterior de maxila. Odontologia Clínico-Científica (Online), 10(3), 285-291.

Garber, D. A., \& Belser, U. C. (1995). Restoration-driven implant placement with restoration-generated site development. Compendium of continuing education in dentistry (Jamesburg, NJ: 1995), 16(8), 796-798.

Gusman, D. J. R., Alves, B. E. S., Matheus, H. R., Sá, D. P., de Araujo, N. J., Fiorin, L. G., \& Almeida, J. M. (2018). Enxerto de tecido conjuntivo para recobrimento de implante dentário em área estética. Archives Of Health Investigation, 7.

Lewis, S. (1995). Anterior single-tooth implant restorations. International Journal of Periodontics \& Restorative Dentistry, 15(1).

Loiola, M., Shibasaki, W., Santos, L. L. D., Vieira, M. C. S. S., Oliveira, M. A. D., Oliveira, M. C. S., \& Ferreira, F. C. (2016). Tratamento interdisciplinar da agenesia dos incisivos laterais superiores: interação entre Ortodontia, Implantodontia e Prótese. Ortodontia, 408-413.

Marcelino, K. P., Souza, J. A. N. de, Ribeiro, D. T., Dantas, E. M., Barbosa, G. A. S., Gondim, A. L. M. F., \& Almeida Neto, L. F. de. (2020). Conduta cirúrgica após perfuração da membrana de Schneider durante sinus lift: relato de caso. Research, Society and Development,9(10), e9959109425. https://doi.org/10.33448/rsd-v9i10.9425

Medeiros, M. S., Marcelino, K. P., Oliveira Júnior, J. C. de, Pinheiro, N. C. G., Freire, J. C. P., Dantas, E. M., Barbosa, G. A. S., Gondim, A. L. M. F., Ribeiro, E. D., \& Almeida Neto, L. F. de. (2020). Exodontia atraumática e implante imediato em área estética: relato de caso. Research, Society and Development, 9(9), e880997997. https://doi.org/10.33448/rsd-v9i9.7997

Oliveira, J. A. D., Ribeiro, É. D. P., Conti, P. C. R., Valle, A. L. D., \& Pegoraro, L. F. (2002). Condicionamento gengival: estética em tecidos moles. Rev. Fac. Odontol. Bauru, 99-104.

Pereira, A. S., Shitsuka, D. M., Parreira, F. J., \& Shitsuka, R. (2018). Metodologia da pesquisa científica. UAB/NTE/UFSM. https://repositorio.ufsm. br/bitstream/handle/1/15824/Lic_Computacao_Metodologia-Pesquisa-Cientifica. pdf.

Shenoy, A., \& Shenoy, N. (2010). Dental ceramics: An update. Journal of conservative dentistry: JCD, 13(4), 195.

Silva, R. A. R., Almeida Neto, L. F. de, Marcelino, K. P., Cardoso, L. C. L., Dantas, E. M., Barbosa, G. A. S., Macêdo, F. C. de, \& Gondim, A. L. M. F. (2020). Osteotomia segmentar da maxila em área estética para viabilizar reabilitação com implantes dentários: relato de caso. Research, Society and Development, 9(9), e594997525. https://doi.org/10.33448/rsd-v9i9.7525.

Souza, R. A. D., D., Ávila, F. A., Barbosa, M. D. C., Sassi, J. F., Rino Neto, J., \& Paiva, J. B. D. (2016). Biomecânica ortodôntica no tratamento reabilitador bucal. Ortho Sci., Orthod. sci. pract, 9(34), 53-64. 